Kriz Dergisi 11 (3): 21-27

\title{
DEPREMI YAŞAYAN ERGENLERIN GELECEK BEKLENTILERININ iÇERIĞj+
}

\author{
Müge Artar*
}

\section{ÖZET}

Amaç: Bu çalışmanın amacı depremi yaşayan ergenlerin, bu travmatik deneyim sonucunda geleceğe ilişkin planlarında değişiklik yapıp yapmadıklarını ve bu planların içeriklerinin neler olduğunu incelemektir. Yöntem: $\mathrm{Bu}$ çalışmada niteliksel yōnteme dayalı görüşmeler kullanılmıştir. 8 kız, 8 erkek olmak üzere toplam 16 deprem yaşantısı olan ve İzmit bölgesinde oturan ergen çalışmaya katılmıştır. Araştırmanın amacına uygun olarak geliştirilen görüşme formu bireylere uygulanmıştır. Görüşmeler deşifre edilerek derinlemesine içerik analizi yapılmıştır. Bulgular: Derinlemesine analizleri yapılan gelecek beklentisi görüşmeleri birçok ergenin gelecek ile ilgili planlarının sayısal olarak diğer yaşıtlarına

+ Bu araştırma 27-31 Ağustos 2003 tarihinde Xl'ci Avrupa Gelişim Psikolojisi Kongresi'nde sunulan bildirinin bir bölümüdür.

* Yard. Doç. Dr., Ankara Üniversitesi Eğitim Bilimleri Fakültesi. oranla, oldukça fazła olduğunu göstermektedir. Bu planların çoğunlukla, bulundukları ili ya da ülkeyi đeğiştirmeye, hiç olmazsa yaşam şartlarını değiştirmeye, yönelik planlar olduğu görülmektedir. $\mathrm{Bu}$ ergenler özellikle yaşıtlarından farklı olarak kișilik özeliiklerini değiştirmeye yönelik çok sayıda plan oluşturmuşlardir. Planlarına ilişkin görüşleri sorulduğunda ergenlerin bunları gerçekleştirmede umutsuz oldukları görülmektedir.

Anahtar Sözcükler: Ergenlik dönemi, gelecek beklentisi, travma, deprem yaşantısı

\section{Contents of Future Orientations of}

\section{Adolescents Who Lived an Earthquake in} 1999

\section{ABSTRACT}

Object: The main aim of this study is to investigate whether adolescents who lived an earthquake changed their plans about their future or not. If they changed their plans, this study tries to find the contents of them. Method: 
In this study a qualitative method used by doing interviews with adolescents. 8 gurls and 8 boys totally 16 adolescent from Izmit region who Ived the earthquake but were not live a close parents loss or a severe damage participated to the study. Interview schedules were developed due to the aims of the study. After Interviews, their transcriptions and deep content analysis were done. Results: Content analysis of the interviews show that earthquake region adolescents put a lot of plans about therr future and they were mostly about changing their city or country or at least to change their ilfe styles. Different from their peers adolescents put a lot of personal characteristic goals like to be more helpful or to have a wisdom Despite all the plans it seems they are hopeless to realise these goals

Key Words: Adolescence, future orientation, trauma, earthquake experience

\section{GiRiş}

Turkıye'de çocuklar, ergenter ve allelerı Ağustos ve Kasım 1999'da yaşamlarını tumuyle değıştıren depremlerı yaşadılar. Deprem sırasında ve devam eden gunlerde bırçok ınsan doğrudan yaşam tehdıdıyle, cıddı yaralanmalarla ve yakınlarının kayıplarıyla karşı karşıya kaldı. Yakınlarının, arkadaşlarının, komşularının kayıplarının yanında, evierını, kışısel eşyalarını yıtırdiler. Butun bu travmatık yaşantılar guniuk yaşamın zorluklarıyla bırleşerek bıreylerın yaşama ıışkın algısını değıştırmıştır. Yaşanan buyuk travmalar sonucunda sosyal katılımda azalma, yaşama ve var olan çevreye duyulan ılgıde azalma, yabancılaşma duyguları le bırlıkte kaygı, depresyon, ve yalnizlık gıbı duygular da gelışır (Hobfoll 1998).

Ergenterın gelecek beklentısı kavramı uzun yıllar bırçok araştırmacının ılgı kaynăğ olmuştur Gelecek beklentısı ergenlerın gelecekle bağlantılı goruş, ılgı ve kaygılarını barındıran bılışsel harıtalardır $\mathrm{Bu}$ alandakı ılk çalışma Gilispie ve Allport (1955) tarafindan on ulkedekı ergenlerın planları sorularak yapıımıștır; benzer şekılde gerçekleştırılen son çalışma ıse Nurmı ve arkadaşları (1999) tarafından 11 ulkede gerçekleştırılmıştır. Tum bu çalışmalarda benzer bır bıçımde başarıya ve kışıler arası Ilışkılere ałt planlar one çıkmaktadır. Ergenler okulu bıtırmek, bır ışte başarılı olmak, unvan sahıbı olmak ve sevgılı bulmak, evlenmek, çocuk sahıbı olmak gibı planları kışilık ozelliklerıne ya da yaşamsal değışıklıklere ıışkın planlardan daha fazla oluşturmaktadırlar.

Ergenlık, yetışkınığe doğru bır yolculuktur. Bu yolculukta; bırçok yol, yon değıştırme, farklı taşıma araçları ve eşlık eden yolcular vardır. Butun yolculuklarda yol harıtaları ve yollardan hangılerının seçıleceğıne ılşkın kararlar buyuk onem taşır. Yollar çoğunlukla bır yere çıkar; bunlardan bazıları yeşı! aydınlık genış bulvarlara, bazıları da dar karanlık arka sokaklara Ama yine de birey bu yolculuklardan, ozellikle de kendısıyle ılgılı, bırçok şey oğrenır. Işte gelecek beklentısı kavramı bu yolculukta seçılecek yolları belırleme bıçımıdır (Nurmı 2001).

Geleceğı planlama oldukça karmaşık bır sureçtır. Temelınde gudulenme, planlama ve değerlendırme olmak uzere uç psikolojık sureç ile tanımlanmaktadır. Insanlar once gudulerı, değerlen ve bektentılerı doğrultusunda geleceğe yonelık amaçlar ortaya koyarlar, kısaca bıreyın geleceğe yonelık ne tur ılgılerı olduğu tantmlanır. Daha sonra bu amaçları gerçekleştırmenın aşamaları oluşturulur, planlar ve problem çozme yollarını duşunülùr; amaçlara nasıl ulaşılacağı 
bulunmaya çalışılır En son olarak bıreyler bu beklentılerıne ulaşma olasılıklarını değerlendırırJer, amaçlarını gerçekleştırme olasılıklarının ne kadar olduğunu bulmaya çalışırłar (Salmela-Aro 2001)

Ergenlerın geleceklerıne yonelık oluşturduklari beklentıler onların yetışkın yaşantılarını belırler, orn ış, yaşam bıçımı, eş seçımı. Ergenlerm geleceklerını nasıl gorduklerı onların kımlık ve benlık oluşumlarını şekıllendırır $\mathrm{Bu}$ alandakı çalışmalar uç temel başlıkta ıncelenebilır

1- Bilşsel ılgıler ve gelecek bekientısıbilşsel uslup, yaratıcılık, soyut duşunce

2- Duygusal durum ve gelecek beklentısibenlık kavramı, denetım odağı, başetme stratejlerı, ıyı olma halı

3. Gelecek beklentısını etkıleyen faktorleraile, okul, sosyo-ekonomı durum

$\mathrm{Bu}$ çalışmada, gelecek beklentısını etkileyen faktorler arasında daha once incelenmemış olan travmatık deneyımın gelecek beklentısı uzerındekı etkısı araştırı́mıştır

Geleceğe ılışkın oluşturulan planların sayısı, ıçerığı, zaman uzaklığı, ve nedensel yuklemlemeler olmak uzere uç temel faktor araştırma bırımlerını oiuşturmaktadır Sayısal çokluk daha fazla gelecek planı yapıldığını, zaman uzaklığı bıreyın gerçekten uzak geleceğın de duşunduğunu nedensel yuklemlemeler ıse bıreyın oluşturduğu planlar ve yaşam hedeflen arasındakı temel bağı gostermektedır

Yetışkınlere oranla ergenler, kendılerının ve toplumun geleceğı ıle tlgilı goruşlerını belırtmekte çok başarılıdırlar (Nurmı 1989) Araştırmalar genellıkle ergenlerın geleceklerıne ılıskın syımser olduklarını gostermektedır (Seıgner 1992, Lanz ve Rosnatı 2002, Confalonierı 2002, Malmberg 2002) Gelecek bağlantılı beklentılerın çoğu yetışkın yaşantısının rollerı olarak karşımıza çıkmaktadır Eğıtım, meslek ve aıle ıle ılgılı planlar, eğlence, gezı gibı etkınlik planlarının onune geçmekte olduğu, butun bunlara karşın ergenlerın gelecek beklentilerinin daha genel, ayrıntıdan yoksun ve hatta kalıplara uygun olduğunu, ayrıntılı planların yaşla birlıkte arttığı gorulmektedir

Daha çok sayıda olumiu beklentı oluşturmanın ıyı olma hal, yuksek benltk saygısı, ve baş etme yollarını kullanma ıle de ılş̧ısı bulunmuştur (Lanz ve Rosnatı 2002, Libreska 2002) Olumsuz beklentıler ve değışken beklentı ıçerkklerının, duşuk ıyı oima halını ve umutsuzluğu tanımladığı soylenmektedır ( Nurmı 2001)

Argaval, ve arkadaşlarının (1983) travmatık durumların ergenlerın gelecek beklentısının sayısını arttırdığı ve yonunu değıştırdığıne Iışkın bulguları kuramı çalışana araştırmacılar tarafından oldukça ılgınç bulunmuştur $\mathrm{Bu}$ araştırmanın bulgularına gore, gelecek beklentısı sadece kısa surelı travma yaşantısında ve kalıcı fızıksel yaşantı olmadığı durumlarda gelışebılmektedır Ev, sureklı bır ış ve toplumsal çevre gıbı kalıcı algılanan özellıklerden yoksunluk, bıreyın yaşamını yenıden sorgulamasına ve gelecekle ılgılı değışı ıçerıklı ve çok sayıda plan oluşturmasına neden olmaktadır

Ergenlerın gelecek beklentılerının ıçerığı, genelıkkle, başarıya ılışkın, ıiş̧kısel, varoluşsal, ve deneysel olmak uzere dort başlıkta toplanmaktadır Başarıya ıisşkin beklentiler çoğuniukla, sınıfı geçmek, okulu bıtırmek, bır meslek sahıbı olmak, unvan ya da mevkı sahıbı olmaya doğru değışmektedır IIışkısel beklentıler genellıkle, 
sevgili bulmak bir eş seçmek, aile kurmak, çocuk sahibi olmak olarak örneklendirilmektedir. Varoluşsal beklentiler; daha iyi bir insan olmak, daha yardımsever olmak gibi bireyin kişisel özelliklerini değiştirmeyi ve toplumsal rolünü sorgulamasını tanımlamaktadır. Deneysel beklentiler ise ülke, iş, yaşam biçimi değiştirmek gibi bireyin yaşamsal durumunu tümūyle değiştirmesine ilişkin planlardır.

$\mathrm{Bu}$ çalışma daha önce araştırmacı tarafından yapılan benzer bir çalışmanın devamı niteliğindedir. İlk çalışma İzmit ve Ankara'da yaşayan ve benzer özellikler taşıyan iki ergen grubuna uygulanan bir ölçek doğrultusunda ergenlerin gelecek beklentisinin sayısının ve türünün karşılaştırılmasıdır (Artar 2002). Íkinci çalışma ise derinlemesine görüşmeler kullanılarak deprem bölgesinde yaşayan ergenlerin gelecek beklentilerinin içeriğinin araştırımasıdır. j̇łk çalışmada uygulanan araç "Gelecek Olayların Yoğuniuğu Görevi", Cottle ve Klineberg (1974) tarafından geliş̧irilmiştir. Araçta açık uçlu tek bir soru ve yönlendirmeler bulunmaktadir. Ergenlerden, kendileriyle ilgili olabildiğince çok plan düşünüp yazmaları istenmekte, daha sonra sayıy artırabilmek için yüreklendirilmekte ve son olarak her plan için olası ulaşılabilecek yaşı kestimeleri istenmektedir. İ k çalışmada eksik olan ergenlerin oluşturduğu planların içerikleri bu planlara iliş̧in nedensel yüklemlemeleri ve planlarına ilişkin duygularıdır.

İlk çalışma sonuçlarına göre, deprem bölgesinde yaşayan ergenler, diğerlerine oranla daha uzun vadeli ve daha çok sayıda plan oluşturmuşlardır. Ankara'da yaşayan ergenlerle karşılaştırıldığında, İzmit grubunda depremi yaşayan ergenlerin gelecek planlarının içeriği beklentilerden çok farklıdır. Bu gruptaki ergenlerin oluşturduğu varoluşsal ve deneysel planların sayıları; başarıya iliş̧in ve iliş̧isel planların sayılarından oldukça yüksektir. Bu bulgular bize deprem gibi travmatik bir olayın gelecek beklentisini gösteren planların sayılarını artı́ıdığını net bir şekilde göstermektedir (Artar, 2002). Bu bulgular incelendiğinde gelecek beklentisj gibj olumlu bir özelliğin travma ile gelişmiş, olması farklı bir incelemenin gerekli olduğunu düşündürmektedir. Bu çerçevede yeni bir çalışmaya gereksinim duyulmuştur. $\mathrm{Bu}$ çalışma travma yaşamış ergenlerin farklılaşan gelecek beklentisi planlarının içerikierini, bu planlara ilişkin nedensel yüklemlemeieri ve duygusal bakışlarınt araştırabilmektir.

\section{YÖNTEM}

\section{Araşturma Grubu}

Çalışma 2001 yli Ekim ayında ł zmit ilinde depremi farklı düzeylerde yaşamış; ama kalıcı bir yaralanma ya da ailesinden ve yakın akrabasından bir kayıp yaşamamış sekizi kız, toplam onaltı ergen ūzerinde gerçekJeştirilmiştir. Ergenlerin yaş aralığı 17-14 ortalama yaşı 15.4'dür. Araştırma grubu orta sosyoekonomik düzeycien gelen bir okula devam eden ve belirtilen niteliklere sahip ergenler arasında gönülülük ilkesi gözetilerek oluşturulmuştur. Araştırma grubundaki ergenler hepsi aynı okulda okumakta, aynı semttte olmasa bile yakın semtlerde yaşamakta olan, orta sosyoekonomik düzeyden ailelerin çocuklarıdır.

\section{Veri Toplama Aract}

Bu çalışmada gelecek beklentisi derinlemesine görüşme ile analiz edilerek gelecek beklentilerinin içeriklełi ve ergenlerin bu beklentilere ilişkin algıları incelenmiştir. Görüşme 
formu araştırmacı tarafından geliştirilımiştir. Görüşme formunun geliştirilmesinde bir önceki çalıșmada ne tür bilgilerin eksik kaldığı sorusundan yola çıkılarak; depremi yaşayan ergenlerin ne tür gelecek planları yaptıkları ve bu planlara yönelik duygularının neler olduğu sorulmuştur. Bir görüşme toplam 8 sorudan oluşmakta ve yaklaşık kırkbeş dakika sürmektedir. Görüşmeler daha sonra deşifre edilerek sınıfianmış ve içerik analizi uygulanmıştır.

\section{BULGULAR}

Derinlemesine analizleri yapılan gelecek beklentisi' görūşmeleri birçok ergenin (\% 85) gelecek ile ilgili planlarının sayısal olarak yaşitlarıyla yapılan diğer çalışmalardaki sayılarla karşılaştırıldığında oldukça fazladır. Tablo 1 'de görüldüğü gibi bu planların çoğunlukla bulundukları ili ya da ülkeyi değiş̧tirmeye (sırasiyla \% 51,\% 47), hiç olmazsa yaşam şartlarını ve kişisel özelliklerini değiştirmeye (vicdanlı olmak\%29; dünyayı gezip insanlara yardım etmek\% 24), yönelik planlar olduğunu göstermektedir. 15 yaşında bir erkek ergenin açıklamaları çarpıcıdır: "Ben mutlaka gideceğim buralardan yani öyle kaçıp gitmek değil benimki, değişik birşeyler yapmam gerekiyor mesela .......'ya gidebilitim orada çok iyi şartlar varmış, olmadı büyük şehirlere giderim ama oralarda deprem riski olmamalı". Bir başka 16 yaşında erkek " ben bu şehirden ayrılmak istiyorum, korkum kesinlikle deprem değil yani deprem bölgesi bir yere de gidebilirim, ama burada sanki hiç birşey aynı değil değişiklik yapmam çok önemli..." demektedir. Kişisel özelliklere ilişsin planlar ilginçtir. Depremi yaşayan ergenler yardımseverlik, vicdanlı olmak, iyi bir insan olmak gibi bireysel özelliklerinde değişiklik yapmak istemektedirler. 15 yaşında bir kız, "Daha önce, hiç aklıma bile gelmeyen şeyleri planliyorum, yani iyi bir insan olmak ve yardımsever olmak çok önemli görünüyor artık, eskiden bana önemli gelmezdi, ama en çok çevremizdeki bu özellikler beni etkiledi depremden sonra." demektedir. 16 yaşında bir erkek, "ben önceden vicdanlı olmak gibi kavramları bilmezdim, hatta dalga bile geçerdik arkadaşlarla aramızda, ama şimdi bunların önemli olduğunu biliyorum, yani insan vicdan sahibi olmazsa öyle geçip gidiyor yardım isteyenin yanından..." diye belirtmiştir.

Planlarına ilişkin ayrıntılar ve zamanlama Tablo-1 Depremi Yaşayan Ergenlerin Gelecek Beklentilerinin Konuları ve Yâzdeleri

\begin{tabular}{|l|l|}
\hline Ergenlerin Gelecek Beklentileri & $\begin{array}{l}\text { Yäzde } \\
\%\end{array}$ \\
\hline Başka bir şehre yerleşmek & 51 \\
\hline Başka bir älkeye gitmek & 47 \\
\hline Daha yardımsever olmak & 38 \\
\hline Daha vicdanlı olmak & 29 \\
\hline Arkadaşlarına yardım eden biri olmak & 27 \\
\hline Dünyayı gezip insanlara yardım etmek & 24 \\
\hline Eğlenceli biri olmak & 18 \\
\hline lyi bir işi olması & 16 \\
\hline Güzel bir aile kurmak & 14 \\
\hline Başarılı olmak & 12 \\
\hline
\end{tabular}

bilgileri istendiğinde bunları çok rahatıkla tanımlamaktadırlar, 15 ergen bu planların bütün ayrıntılarını oluşturduklarından söz etmektedir. Sadece bir ergen (16 yaş kız) bu planların hiçbir ayrıntısını düşünmediğini dile getirmektedir.

Deprem bölgesinde yaşayan ve çok sayıda 
varoluşsal ve deneysel plan oluşturan ergenlerın bu planlarını ozellikle yaşamlarında koklu değışıklıkler yapma ısteğıne bağlı olarak oluşturdukları gorulmektedir Ergenler çok sayıda ve ıyımser gorunen bu planlarını yapmakla burfıkte bu planların gerçekleşmesı konusunda umutsız bır tablo sergılemektedırler "Pekı sence gerçekleşır mı bu planlar?" dıye sorulduğunda genelılıle burbırlerıne benzer cevaplar vermektedırler Onaltı yaşında bır kız ergen, "Aslında yapılmaz dıye bır şey yok, fakat ben pek umutlu değılım kendımden, planlarken ıyı de yapma zamanı gelınce insan korkuyor" demektedir

\section{TARTIŞMA VE SONUÇ}

Depremı yaşayan ergenler, bırçok ulkede ve Turkıye'de yaşayan, ancak deprem yaşamayan ergenlere oranla, başarıya ve ılşkıllere ıısşkın değı, yaşamını ya da bıreysel ozelikklerıı değıştırmeye ilişkın çok sayıda plan oluşturmuşlardır (Seıgner ve Halabı-Kheır 1988, McCabe ve Douglas 2000, Artar 2002) Brreydeki duygusal değışıklıkerın bıreyın gelecek beklentısı oluşturmada anahtar rol oynadığı goruşu bu çalışmanın sonuçları ıle oldukça tutarlı gorunmektedır (Nuttın, 1984)

Ergenlerın gelecek planlarının gerçekleşmesıne ilışkın umutsuz oldukları bulgusu, onların, bu travmatık yaşantı sonucunda bır değışıklık yaşadıklarını gostermektedır
Bırçok çalışma bu tur bır durum yaşamayan ergenlerın geleceklerıne yonelık ıyımser olduklarını gostermektedır (Nurmı 1989, Poole ve Cooney 1987) Ayrıca Emmons (1991) ve Salmela-Aro ve Nurmı (1997a, 1997b) yaptıkları çalışmalarında, başarı ve ılışkısel beklentılerın çokluğunun yuksek ıyı olma halını tanımladığını ve deneysel ve varoluşsal planların Ise duşuk ıyı olma halını ışaret ettığını belırtmektedırler $\mathrm{Bu}$ araştırma sonuçları deprem bolgesınde yaşayan ergenlerın varoluşsal ve deneysel planlarına eşlık eden umutsuzluk duygularını açıklar niteliktedır

Depremı yaşamak ergenlerın gelecek ıle Ilgilı planlarının sayısını artırmakla bırlıkte yapısını da tamamen değıştırmış gorunmektedır Ergenler, ellerındekı somut varlıklarla bağlarının yok olduğu (butun eşyalarını kaybetmek gıbı) ve topluluk olarak benzer problemler yaşađtkları ıçın bıreysel ve yaşamsal değışımler ıstemekte, fakat kendılerınde gerçekleştırme gucunu bulamamaktadırlar Bu sonuç, uzerınden çok uzun zaman geçse bıle depremı yaşayan ergenlerın ve bolgenın hala destek hızmetlerıne gereksınımi olduğunu gostermektedır

\section{KAYNAKLAR}

Argarwal A, Tripathı, KK, Srivastava $M$ (1983) Social roots and psychological implications of time perspective International Journal of Psychology, 18 $367-380$
Artar M (2002) Compartson of future time per spective of adolescents from earthquake and nonearthquake regıons in Turkey (Içınde) Adolescents Future Orientation Theory and Research (Eds) Trempala $T$ Malmberg LE, European University Studies Peter Lang, Frankfurt 
Confolonien $E$ (2002) A narrative perspective on the future Transition to adulthood (Içinde) Adolescents' Future Orientation Theory and Research (Eds) Trempala T, Malmberg LE, European University Studies, Peter Lang, Frankfurt

Cottle TJ, Kltneberg S (1974) The Present of Things Future, Mac Mullan Press, New York

Emmons R A (1991) Personal strivings, daly lfe events and psychological and physical well-being Journal of Personality, 59 455-472

Gillispie JM, Allport GW (1955) Youth's outlook on the future (a cross-national study), Doubleday Company, New York

Hobfoll SE (1998) Stress culture and communty, Plenıum Press, New York

Lanz M, Rosnatı R (2002) Adolescents' and young adulls' construction of the future effects of family relations, sel-esteem, and sense of coherence (Içınde) Adolescents' Future Orientation Theory and Research (Eds) Trempala T, Malmberg LE, European University Studies, Peter Lang, Frankfurt

Libreska $\mathrm{H}$ (2002) Life perspectives of adoles. cents in the context of soctal and economic changes In Poiand (içınde) Adolescents' Future Onentation Theory and Research, (Eds) Trempala T, Malmberg LE, European University Studies, Peter Lang, Frankfurt

Malmberg LE (2002) Adolescents' brased means and future expectations (Içınde) Adolescents' Future Orientation Theory and Research (Eds) Trempala $T$, Malmberg LE European University Studies, Peter Lang, Frankfurt

McCabe K, Douglas B (2000) First comes work, then comes marriage Future onentation among African American young adolescents Family Relations, 49 (1) 63-68

Nurmı JE (1989) Planning, motivation and evaluation in orientation to the future a latent structure analysis Scandinavian Journal of Psychology, 30 64-71

Nurmı JE (2001) Navigating through adolescence Introduction (Içinde) Navigatıng through adolescence (Ed) Nurmi JE, European Perspectives, Routiedge, New York

Nurmf JE, Liceanu A, Libreska H (1999) Time perspective of polısh yought (Içınde) The adolescent experience European and American adolescents in the 1990's (Ed) Alsaker FD, Flammer A, Mahwah N J, Lawrance Erlbaum, NJ

Nuttin JR (1984) Motivation planning, and action $A$ relational theory of behavior dynamics Htllsdale, Lawrance Erlbaum, NJ

Poole ME, Cooney GH (1987) Orientations to the future A comparison of adolescents in Australia and Singapore Journal of Youth and Adolescence, $16129-151$

Salmela-Aro K (2001) Personal goals during the transition to young adulthood (Içinde) Navigating through adolescence (Ed) Nurm! JE, European Perspectives, Routledge, New York

Salmela-Aro K, Nurmt JE (1997a) Goal contents, well being and life context during transition to university A longitudinal study International Journal of Behavioral Development, 20 471-491

Salmela-Aro K, Nurmı JE (1997b) Positive and negative self-related goals and subjective well-being A prospective study Journal of Adult Development, 4 179-188

Seigner R (1992) Future orientation Age related differences among adolescent females Journal of Youth and Adolescence, $21 \quad 421-437$

Seginer $R$ ve Halabi-Kherr $H$ (1998) Adolescent passage to adulthood Future orientation in the context of culture, age and sex International Journal of Intercultural Relations, 22 309-328 